\title{
Vasculogenic mimicry of human ovarian cancer cells: Role of CD147
}

\author{
DANILO MILLIMAGGI $^{1 *}$, MARIANNA MARI ${ }^{1 *}$, SANDRA D' ASCENZO $^{1}$, \\ ILARIA GIUSTI $^{1}$, ANTONIO PAVAN ${ }^{2}$ and VINCENZA DOLO ${ }^{1}$ \\ ${ }^{1}$ Department of Health Sciences, L'Aquila University, L'Aquila; ${ }^{2}$ Department of \\ Experimental Medicine, University of Rome 'La Sapienza', Rome, Italy
}

Received March 23, 2009; Accepted May 11, 2009

DOI: 10.3892/ijo_00000460

\begin{abstract}
The term vasculogenic mimicry (VM) indicates the process by which aggressive tumor cells are able to generate in vitro non-endothelial cell-lined channels delimited by extracellular matrix. Although VM has been described in several human malignancies, the molecular basis of this phenomenon is not entirely understood. In the present study, we examined VM in two ovarian cancer cell lines with different invasion capability (CABA I, low invasion activity; SKOV3, high invasion activity). Specifically, we focused on the potential role played by CD147/extracellular MMP inducer, a membrane spanning molecule highly expressed in tumor cells, in VM. Previous studies have shown that CD147 may be involved in the progression of malignancies by regulating the expression of metalloproteinases in peritumoral stromal cells. In this study, we found significant correlations between expression of CD147 in ovarian cancer cell lines and tumor invasiveness, the activity of the proteases and the ability to form vascular channels. The treatment of SKOV3 cells with small interfering RNA against CD147 suppressed the ability of these cells to generate non-endothelial cell-lined channels. In contrast, transfection of CD147 cDNA into the CABA I cell line resulted in an increased tumor invasiveness and enabled the formation of vascular channels. Altogether, our data suggest that CD147 may play a critical role in VM of CABA I and SKOV3, human ovarian cancer cell lines.
\end{abstract}

\section{Introduction}

Tumors require a blood supply for growth and hematogenous dissemination $(1,2)$. The term angiogenesis describes the formation of new vessels by sprouting of differentiated endothelial cells from pre-existing vessels (3). In contrast to

Correspondence to: Dr Vincenza Dolo, Dipartimento di Scienze della Salute, Università dell'Aquila, Via Vetoio-Coppito 2, I-67100 L'Aquila, Italy

E-mail: giovenza5@virgilio.it

${ }^{*}$ Contributed equally

Key words: vasculogenic mimicry, CD147, ovarian cancer, angiogenesis angiogenesis, vasculogenesis describes the formation of new vessels independent from pre-existing vessels. Several authors have recently reported a process termed vasculogenic mimicry (VM), which consists of the formation of patterned, tubular networks by aggressive tumor cells in three-dimensional cultures in vitro, that mimics endothelial-formed vasculogenic networks (1,4,5-12). In vasculogenic mimicry, tumor cells generate non-endothelial microcirculatory channels composed of extracellular matrix and lined externally by tumor cells (13).

VM has been described in several types of aggressive tumors, including cutaneous, uveal and mucous membrane melanoma, inflammatory and ductal carcinoma of the breast, ovarian and prostatic carcinoma, synovial sarcoma, rhabdomyosarcoma, osteosarcoma and pheochromocytoma. There is evidence to suggest that the matrix metalloproteinase 2 (MMP-2) and its activator, the membrane-type 1 matrix metalloproteinase (MT1-MMP), may play a role in VM $(14,15)$. CD147, also named EMMPRIN (Extracellular Matrix MetalloPRoteinase Inducer) or basigin, is a plasma membrane glycoprotein enriched on the surface of many malignant tumor cells and functions as an upstream modulator of metalloproteinase production in the local tumor environment $(16,17)$. CD147-positive tumor cells stimulate neighboring fibroblast cells to express MMPs and therefore facilitate tumor invasion and metastasis. Recent investigations have provided evidence that CD147 plays a crucial role in cancer progression not only by inducing MMP production (18-25) but also by stimulating tumor angiogenesis via induction of vascular endothelial growth factor (VEGF) expression (26).

Data on the pathophysiologic role of CD147 in VM are scarce. In this context, the aim of our study was to investigate the potential role played by CD147 in VM. We examined our hypothesis in two ovarian cancer cell lines with different invasion capability (CABA I, low invasion activity; SKOV3, high invasion activity).

\section{Materials and methods}

Cell culture. The CABA I cell line was established from the ascitic fluid of an ovarian carcinoma patient not undergoing drug treatment (27). CD147-transfected CABA I cells were maintained as monolayers in RPMI-1640 (Euroclone, Devon, 
UK) containing 5\% FCS and $400 \mu \mathrm{g} / \mathrm{ml} \mathrm{G} 418$. Human ovarian carcinoma cell lines SKOV3 cells were cultured in RPMI medium containing $10 \%$ FCS.

Small interfering RNA and transfection. Transfection of CD147/green fluorescent protein cDNA (a kind gift of S. Zucker) into human CABA I ovarian cancer cells with low CD147 expression was performed by the method of Zucker et al (28). Cells were stably transfected using the FuGene (Roche, Basel, Switzerland) according to the manufacturer's protocol. G418-resistant clones were microscopically screened for green fluorescent protein fluorescence and positive clones were pooled to minimize clonal variations. Control transfectants carrying the pcDNA3 vector alone were generated. Identical results were obtained with non-transfected CABA I cells or CABA I cells transfected with pcDNA3 (data not shown). We silenced CD147 in SKOV3 cells by using CD147 small interfering RNA (siRNA h) sc-35298, scrambled oligos sc-37007 as control, and sc-29528 siRNA transfection reagent (Santa Cruz Biotechnology, Santa Cruz, CA) according to the manufacturer's protocol. The same results were obtained with non-silenced SKOV3 cells or SKOV3 cells transfected with scrambled oligos.

Zymography. Zymography was performed using SDSpolyacrylamide gels copolymerized with $1 \mathrm{mg} / \mathrm{ml}$ gelatin type B (Sigma). Five-fold concentrated cell-conditioned medium were diluted in SDS-PAGE sample buffer under non-reducing conditions without heating. After electrophoresis, gels were washed twice for $30 \mathrm{~min}$ in $2.5 \%$ Triton $\mathrm{X}-100$ at room temperature and incubated overnight in collagenase buffer (50 mM Tris- $\mathrm{HCl}, \mathrm{pH} 7.4,10 \mathrm{mM} \mathrm{NaCl}$, $0.02 \% \mathrm{NaN}_{3}$, and $\left.5 \mathrm{mM} \mathrm{CaCl}_{2}\right)$ at $37^{\circ} \mathrm{C}$. Gels were stained with Comassie Blue R 250 (Bio-Rad, Segrate, Italy) in 30\% methanol and $10 \%$ acetic acid for $2 \mathrm{~h}$ and destained in the same solution without dye. Gelatinase activity was visualized as clear bands on a dark background, indicating proteolysis of the substrate. The supernatant of WM983A melanoma cells was used as a reference standard for MMP-9.

Western blot analysis of CD147. Cells were lysed in buffer containing $50 \mathrm{mM}$ Tris ( $\mathrm{pH} 7.8$ ), $150 \mathrm{mM} \mathrm{NaCl}$, and $1 \%$ NP40. Protein concentration of cell lysate and microvesicles was determinated as described above. Cell lysates $(40 \mu \mathrm{g})$ were resolved by sodium dodecyl sulfate $10 \%$ polyacrylamide gel electrophoresis (SDS-PAGE) under non-reducing and reducing conditions and then transferred to nitrocellulose membranes (Schleicher \& Schuell, Dassel, Germany). Nonspecific binding sites were blocked by incubation with $10 \%$ non-fat dry milk in TBST for $1 \mathrm{~h}$ at room temperature. The blots were incubated with a monoclonal antibody raised against human CD147 (8D6 mouse monoclonal $\mathrm{IgG}_{1}, 1: 500$ dilution; Santa Cruz Biotechnology) for $1 \mathrm{~h}$, followed by peroxidase-conjugated secondary antibody in blocking buffer. After washing, reactive bands were visualized using a chemiluminescence detection kit (ECL, Amersham-Pharmacia Biotech, Piscataway, NJ).

Formation of vascular channels. CABA I, CABA I-CD147, SKOV3 and SKOV3 si-CD147 cells were seeded at 70,000 per well in Matrigel-coated 24-well culture plates with a cellular growth medium containing $10 \%$ serum. SKOV3 and CABA I-CD147 cells were also plated with a cellular growth medium containing 10\% FCS and 500 nM CTT (MMPs inhibitor) (29).

At 2 and $24 \mathrm{~h}$, the formation of vascular channels was photographed and independently scored in a blinded manner by two observers. Periodic acid Schiff (PAS) staining was performed on SKOV3 cells plated on Matrigel to identify the glycogen and related mucopolysaccharides secreted by the cells to form the extracellular matrix-rich vascular channels (30).

Real-time polymerase chain reaction. Total RNA was isolated by using SV Total RNA Isolation System (Promega, Madison, WI) and cDNA was synthesized from $5 \mu \mathrm{g}$ RNA by using the ImProm-II Reverse Transcription System (Promega) according to the manufacturer's protocol. Each real-time polymerase chain reaction (PCR) reaction was prepared in triplicate and contained $2.0 \mu \mathrm{l}$ of cDNA. PCR was carried out using SYBR-green detection of PCR products in real time (Roche). The sequences of the primers used for PCR were as follows: MT1-MMP forward, 5'-GAGCTC AGGGCAGTGGATAG-3', MT1-MMP reverse 5'-GGT AGCCCGGTTCTACCTTC (215 bp); MMP-1 forward, 5'-A GGTCTCTGAGGGTCAAGCA-3', MMP-1 reverse, 5'-CTG GTTGAAAAGCATGAGCA (111 bp); MMP-2 forward, 5'-C ACTTTCCTGGGCAACAAAT-3', MMP-2 reverse, 5'-TGA TGTCATCCTGGGACAGA-3' (257 bp); MMP-9 forward, 5'-TTGACAGCGACAAGAAGTGG, MMP-9 reverse, 5'-GCC ATTCACGTCGTCCTTAT-3' (179 bp); GADPH forward 5'-G GCCTCCAAGGAGTAAGACC-3', GADPH reverse 5'-A GGGGTCTACATGGCAACTG-3' (147 bp). A comparative $\Delta \mathrm{Ct}$ method was used to determine gene expression. Expression levels were normalized to the expression levels of the housekeeping gene GADPH.

Invasion assay. Cell invasion was assayed using modified Boyden chambers with polycarbonate PVP-free Nucleopore filters (pore size, $8 \mu \mathrm{m}$ ) (31). Filters were coated with a thick layer of reconstituted basement membrane $(0.5 \mathrm{mg} / \mathrm{ml}$ Matrigel; Becton-Dickinson, Bedford, MA), which cells must degrade during the migratory process. Cells were resuspended at a concentration of $5 \times 10^{5}$ cells $/ \mathrm{ml}$ in a serum-free medium and added to the upper compartment of the chamber. After 6 h, filters were stained with Crystal Violet $1 \%$ in methanol, and migrated cells in 10 high-power fields were counted.

Statistical analysis. All data shown are from at least three independent experiments and are expressed as mean \pm SD. Statistical significance was determined by using the MannWhitney U test. Calculations were performed using GraphPad Prism 4 software (GraphPad, San Diego, CA). Statistical significance was set at $\mathrm{P}<0.05$.

\section{Results}

Vasculogenic mimicry of ovarian cancer cells. To verify whether ovarian cancer cell lines are capable of generating patterned vascular channels through vasculogenic mimicry, CABA I and SKOV3 cells were seeded onto a 3D matrix 
$\mathbf{A}$

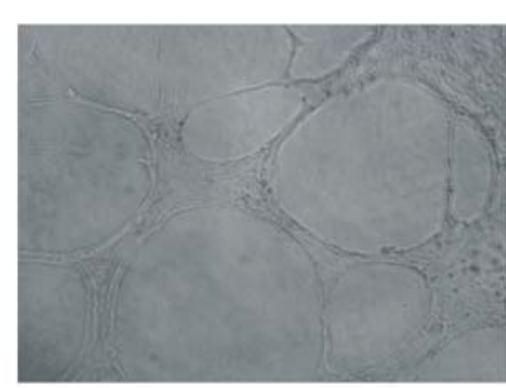

\section{B}
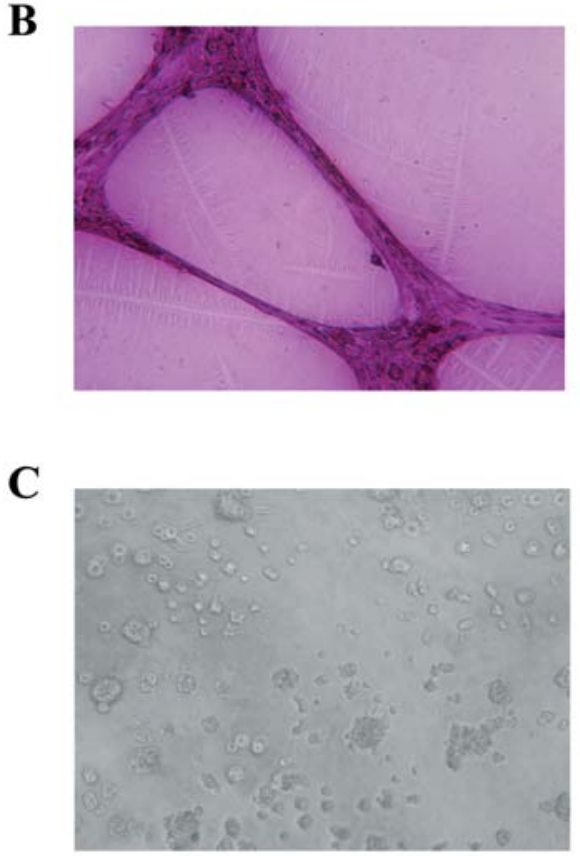

D

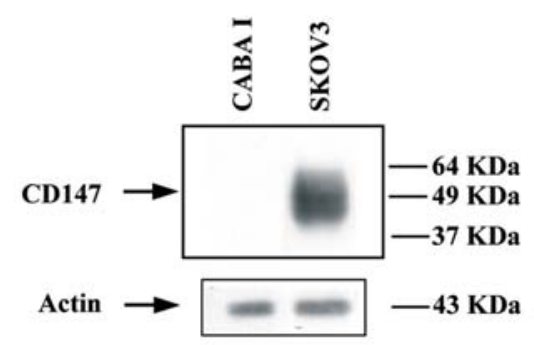

E

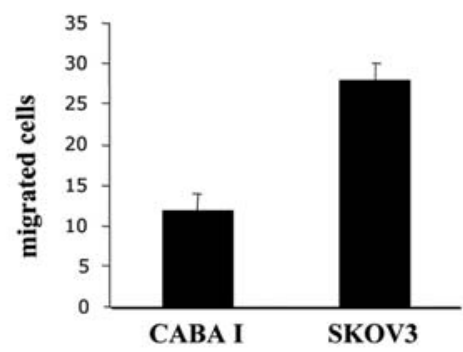

F

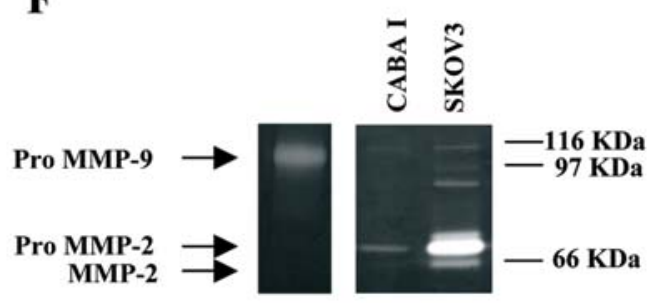

Figure 1. (A and C) Formation of vascular channels by ovarian cancer cells. SKOV3 and CABA I were plated on Matrigel in complete medium containing $10 \%$ serum (magnification, x100). (B) PAS staining analysis of vascular channels formed by SKOV3 cells, using magnification, x125. (D) Western blot analysis of CD147 in CABA I and SKOV3 cells. (E) Comparison of invasive ability of ovarian cancer cells. Data (mean and SD of triplicates) represent the number of migrated cells in 10 high-power fields. Results are representative of three independent experiments. (F) Gelatin zymography of CABA I- and SKOV3-conditioned media.

(Matrigel). In complete medium containing $10 \%$ serum, SKOV3 cells were able to form vascular channels after 2 and $24 \mathrm{~h}$ (Fig. 1A), whereas this was not the case for CABA I cells (Fig. 1C). PAS staining was performed on SKOV3 cells plated on Matrigel to identify the extracellular matrixassociated vascular channels formed by cells (Fig. 1B).

Correlation between CD147 expression levels and proteolytic and invasion capability of ovarian cancer cell lines. The expression of CD147 in ovarian cancer cell lines was assessed by Western blot analysis. A high level of expression was found in the SKOV3 cells, whereas CABA I cells did not express CD147 (Fig. 1D). The invasive capability of SKOV3 cells was higher than that of CABA I as assessed by an in vitro invasion assay using Matrigel (Fig. 1E). Gelatin zymography was performed to examine the presence of matrix-degrading proteases in cell conditioned media (Fig. 1F). The conditioned medium of SKOV-3 cells showed higher proMMP-2 and proMMP-9 activities as compared with the conditioned medium of CABA I cells.
CD147 regulates MMPs expression and plays a role in VM of ovarian cancer cell lines. To investigate the role played by CD147 in tumor progression, we compared CD147transfected CABA I cells with vector-transfected CABA I cells. Expression of the CD147 fusion protein was confirmed by Western blot analysis (Fig. 2A). The invasive capacity and MMP activity was higher in CD147-transfected CABA I compared with vector-transfected cells (Fig. 2B and C). Real-time PCR was performed to quantify MT1-MMP, MMP-2 and MMP-9 gene expression in CABA I CD147transfected cells relative to the parental CABA I population. CD147-transfected cells showed a higher expression of MT1MMP, MMP-2 and MMP-9 (Fig. 2D). To investigate the vasculogenic potential of CABA I CD147-transfected cells, we seeded these cells onto Matrigel-coated wells in complete medium containing 10\% serum. After 24 h, CABA I CD147transfected cells were found to form vascular channels (Fig. 2E), whereas this was not the case for vector-transfected CABA I cells (Fig. 2F). To evaluate that the activity of MMPs induced by CD147 causes for VM, CABA I-CD147 cells 

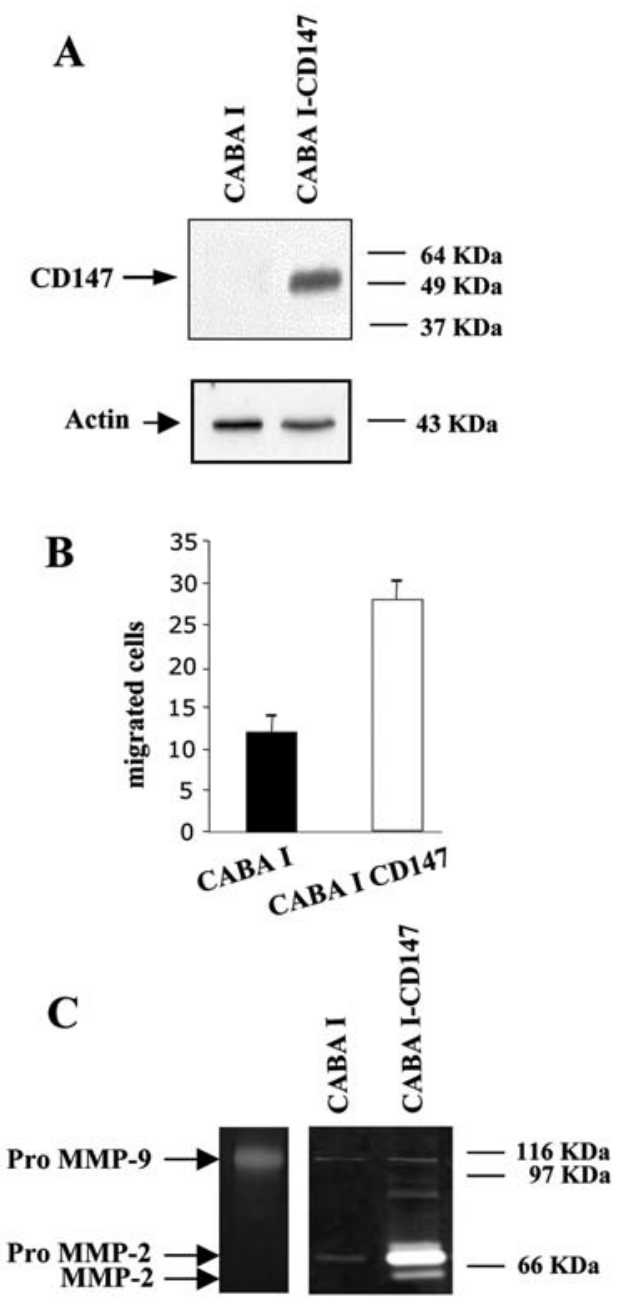
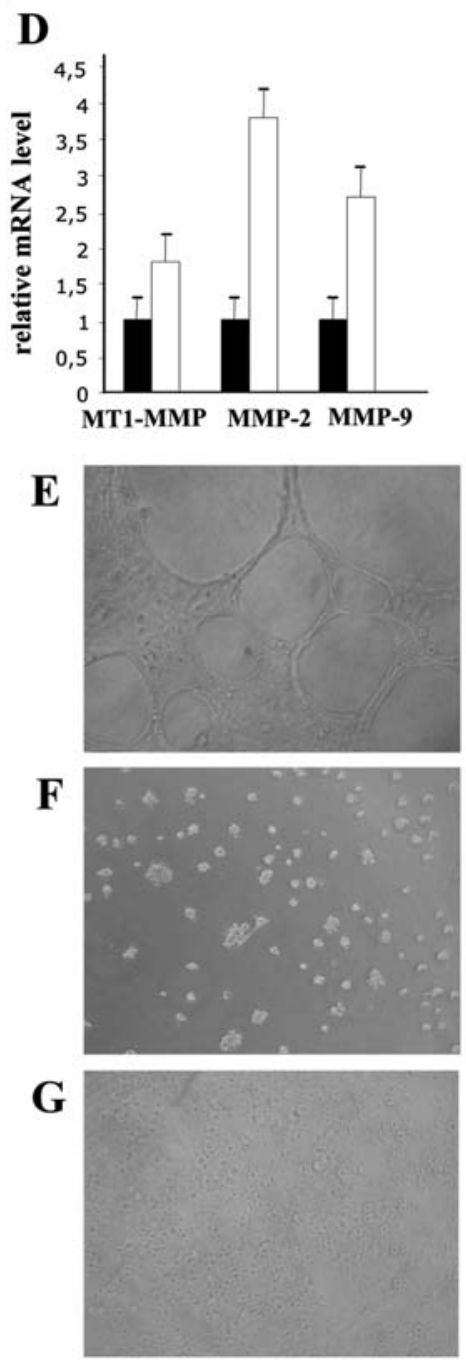

Figure 2. (A) Western blot analysis of CD147 in CABA I and CABA I-CD147 cells. (B) Comparison of invasive ability of ovarian cancer cells. Data (mean and SD of triplicates) represent the number of migrated cells in 10 high-power fields. Results are representative of three independent experiments. (C) Gelatin zymography of CABA I- and CABA I-CD147-conditioned media. (D) RT-PCR data for MT1-MMP, MMP-2, -9 expression in ovarian cancer cells. MMPs mRNA expression in control cells was arbitrarily set at 1 . Formation of vascular channels by ovarian cancer cells. CABA I-CD147 (E), CABA I (F) and CABA I-CD147 with $500 \mathrm{mM}$ CTT (G) cells were plated on Matrigel with complete medium containing 10\% serum (magnification, x100).

were treated with $500 \mathrm{mM}$ CTT. The inhibition of vascular channel formation in the presence of MMP inhibitor is shown in Fig. $2 \mathrm{G}$.

We also examined the invasive potential of SKOV3CD147 silenced cells compared with parental SKOV3 cells. We silenced CD147 in SKOV3 cells by using CD147 small interfering RNA (siRNA). Silencing was confirmed by Western blot analysis (Fig. 3A). SKOV3 cells with silenced CD147 showed lower invasive potential and a marked inhibition in the proMMP-2 and a weak inhibition of proMMP-9 activity as compared to parental SKOV3 cells (Fig. 3B and C). Real-time PCR was performed to quantify MMP gene expression in cells transfected with siRNA relative to the parental SKOV3 population. Cells with silenced CD147 expression showed a marked inhibition in the MT1-MMP, MMP-2, and MMP-9 gene expression (Fig. 3D). Differently from parental SKOV3 cells, SKOV3 cells with silenced CD147 showed a reduced expression, and were not able to form vascular channels when seeded in a three-dimensional matrix (Fig. 3E and F). When SKOV3 cells, plated with a cellular growth medium containing $10 \%$, FCS were treated with $500 \mathrm{mM} \mathrm{CTT}$, their capability to form vascular channel was inhibited (Fig. 3G).

\section{Discussion}

The growth of cancers is dependent upon vascularization, assuring supplying oxygen and nutrients and removing waste products. The best-known mechanism driving tumor vascularization is angiogenesis, consisting in the formation of new blood vessels from the endothelium of the existing vasculature. However, several studies have now been published that suggest that not only angiogenesis but also vasculogenesis may be involved in response to pathological conditions such as tumor formation. Vasculogenesis is the process by which the primordial microcirculation is formed during embryogenesis. The term 'vasculogenic mimicry' has been used to describe the manner in which highly aggressive tumor cells are able to form vasculogenic-like networks similar to embryonic vasculogenesis (32). The patterned 
A

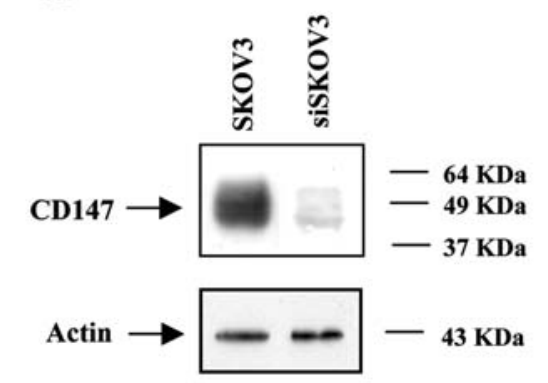

B

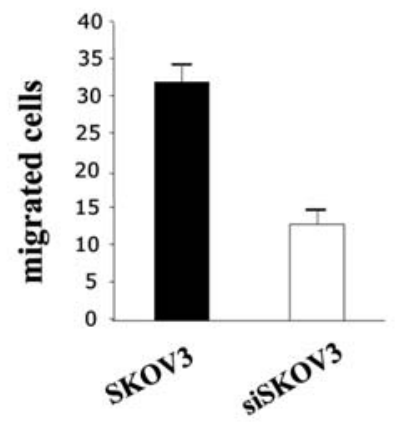

C

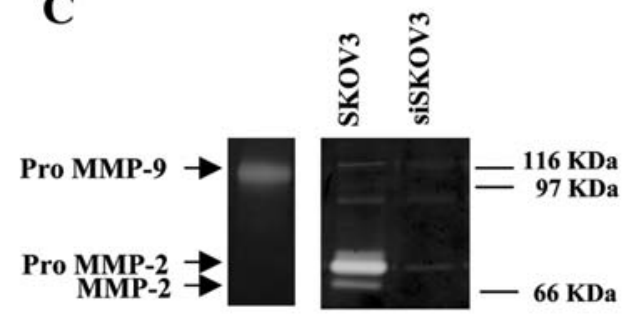

D

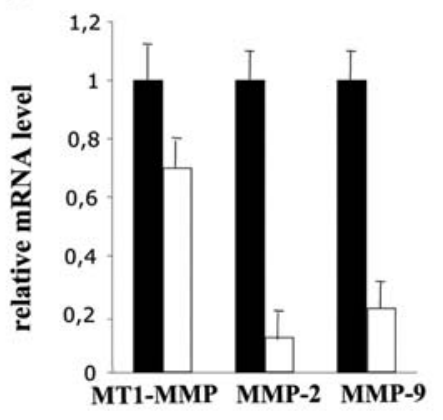

E

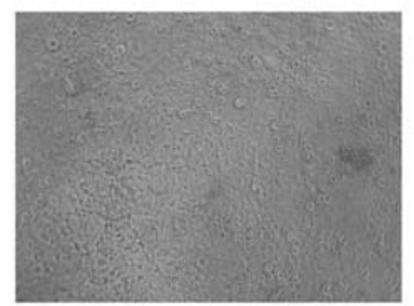

F

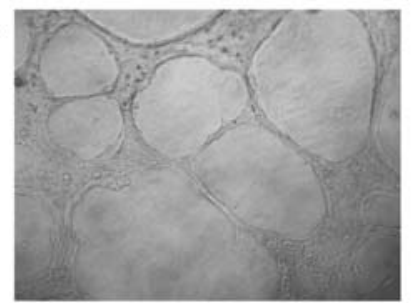

G

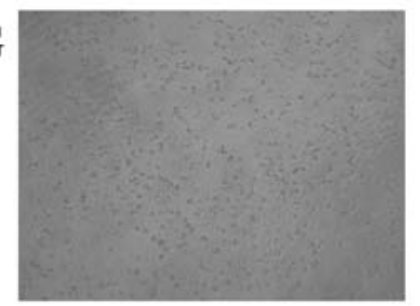

Figure 3. (A) Western blot analysis of CD147 in SKOV3 and siCD147-SKOV3 cells. (B) Comparison of invasive ability of ovarian cancer cells. Data (mean and SD of triplicates) represent the number of migrated cells in 10 high-power fields. Results are representative of three independent experiments. (C) Gelatin zymography of SKOV3- and siCD147-SKOV3-conditioned media. (D) RT-PCR data for MT1-MMP, MMP-2, -9 expression in ovarian cancer cells. MMPs mRNA expression in control cells was arbitrarily set at 1. Formation of vascular channels by ovarian cancer cells. siCD147-SKOV3 (E), SKOV3 (F) and SKOV3 with $500 \mathrm{mM}$ CTT $(\mathrm{G})$ cells were plated on Matrigel with complete medium containing 10\% serum (magnification. x100).

microcirculation characteristic of vasculogenic mimicry was described for the first time in uveal (intra-ocular) melanoma (1). Specifically, vasculogenic mimicry refers to abnormal vessel development in which cancer cells directly line vessels or blood channels within tumors.

Previous studies have shown that aggressive melanoma cells are capable of expressing endothelium-associated genes and to form vasculogenic-like networks in three-dimensional cell cultures $(1,4,5-12)$. There are three key factors that govern the formation of a microcirculation by cells other than endothelial cells in vascular mimicry, namely the plasticity of highly malignant and invasive cells, extracellular matrix remodeling, and the connection of the host vessels via vascular mimicry to acquire a blood supply (32).

Previous studies have shown that highly aggressive melanoma cells are able to behave like blood vessel cells by expressing high levels of matrix metalloproteinases $(14,15)$. We thus hypothesized that the same phenomenon could occur in aggressive ovarian cancer cells. In particular, in this study we focused on the potential role played by CD147 in vascular mimicry of ovarian cancer cells. CD147 expressed on tumor cells plays a key role in triggering the production of matrix metalloproteinases by surrounding stromal cells and tumor cells themselves. In the present study, we examined vascular mimicry in two ovarian cancer cell lines with different invasion capability (CABA I, low invasion activity; SKOV3, high invasion activity). Our results showed that only the highly aggressive SKOV3 cells were able to generate patterned vascular channels when seeded in a threedimensional collagenous matrix (Matrigel). Interestingly, a positive correlation was seen between the cell expression of CD147 and ovarian cancer cell invasive ability and protease activity. In turn, transfection of CD147 cDNA into the CABA I cell line resulted in increased invasion, increased expression of MMP-2 and MMP-9 in both active and proenzymatic form. We believe that ovarian cancer cells can secret and activate MMP-2 and MMP-9, and that remodelling the extracellular matrix can assist the formation of VM. Notably, 
CD147-transfected CABA I cells were able to form vascular channels when seeded in a three-dimensional matrix. In contrast, the treatment of SKOV3 cells with siRNA against CD147 resulted in a suppression of their invasive potential and matrix metalloproteinase activity. As expected, SKOV3 cells with silenced CD147 expression were unable to form capillary-like structures when tested in the Matrigel assay.

Altogether, our results provide strong in vitro evidence that CD147 plays an important role in the formation of tumor-lined vessels by ovarian cancer cells. It is intriguing to speculate that the use of anti-CD147 therapeutic targeting may provide a novel opportunity to circumvent the ability of CD147-expressing tumors, such as ovarian cancers, to grow and metastasize.

\section{Acknowledgements}

We are indebted to Dr Enzo Emanuele for expert editorial assistance.

\section{References}

1. Maniotis AJFR, Hess A, Seftor EA, et al: Vascular channel formation by human melanoma cells in vivo and in vitro: vasculagenic mimicry. Am J Pathol 155: 739-752, 1999.

2. Fukumura D, Xavier R, Sugiura T, et al: Tumor indution of VEGF promotor activity in stromal cells. Cell 94: 715-725, 1998.

3. Hendrix MJC, Seftor EA, Hess AR and Seftor REB: Vasculogenic mimicry and tumor-cell plasticity: lesson from melanoma. Nat Rev 3: 411-421, 2003.

4. Seftor EA, Meltzer PS, Kirschmann DA, et al: Molecular determinants of human uveal melanoma invasion and metastasis. Clin Exp Metastasis 19: 233-246, 2002.

5. Folberg R, Hendrix MJC and Maniotis AJ: Vasculogenic mimicry and tumor angiogenesis. Am J Pathol 156: 361-381, 2000.

6. Folberg R, Rummelt V, Parys-Van Ginderdeuren R, Hwang T, Woolson RF, Pe'er J and Gruman LM: The prognostic value of tumor blood vessels morphology in primary uveal melanoma. Ophthalmology 100: 1389-1398, 1993.

7. Makitie T, Summanen P, Tarkkanen A and Kivela T: Microvascular loops and networks as prognostic indicators in choroidal and ciliary body melanomas. J Natl Cancer Inst 91: 359-367, 1999.

8. Sakamoto T, Sakamoto M, Yoshikawa H, Hata Y, Ishibashi T, Ohnishi Y and Inomata H: Histologic findings and prognosis of uveal malignant melanoma in Japanese patients. Am J Ophthalmol 121: 273-283, 1996.

9. Seregard S, Spangberg B, Juul C and Oskarsson M: Prognostic accuracy of the mean of the largest nucleoli, vascular patterns, and PC-10 in posterior uveal melanoma. Ophthalmology 105: 485-491, 1999.

10. Thies A, Mangold U, Moll I and Shumacher U: PAS-positive loops and networks as a prognostic indicator in cutaneous malignant melanoma. J Pathol 195: 337-342, 2001.

11. Warso MA, Maniotis AJ, Chen X, et al: Prognostic significance of periodic acid-Schiff-positive patterns in primary cutaneous melanoma. Clin Cancer Res 7: 473-477, 2001.

12. Rummelt V, Mehaffey MG, Campbell RJ, et al: Microcirculation architecture of metastases from primary ciliary body and choroidal melanomas: Am J Ophthalmol 126: 303-305, 1998.

13. Folberg RMA: Vasculogenic mimicry. APMIS 112: 508-525, 2004.
14. Seftor RESE, Koshikawa N, Meltzer PS, Gardner LM, Bilban M, Stetler-Stevenson WG, Quaranta V and Hendrix MJ: Cooperative interactios of laminin $5 \gamma 2$ chain, matrixmetalloproteinase-2, and membrane type-1-matrix/metalloproteinase are required for mimicry of embrionic vasculogenesis by aggressive melanoma. Cancer Res 61: 6322-6337, 2001.

15. Seftor RESE, Kirshmann DA and Hendrix MX: Targeting the tumor microenvironment with chemically modified tetracylines: inibition of laminin $5 \gamma 2$ chain promigratory fragments and vasculogenic mimicry. Mol Cancer Ther 1: 1173-1179, 2002.

16. Biswas C, Zhang Y, De Castro R, Guo H, Nakamura T, Kataoka $\mathrm{H}$ and Nabeshima K: The human tumor cell-derived collagenase stimulatory factor (renamed EMMPRIN) is a member of the immunoglobulin superfamily. Cancer Res 55: 434-439, 1995.

17. Ellis SM, Nabeshima K and Biswas C: Monoclonal antibody preparation and purification of a tumor cell collagenase stimulatory factor. Cancer Res 49: 3385-3391, 1989.

18. Plette M, Gilles C, Marchand V, et al: Tumor collagenase stimulatory factor (TCSF) expression and localization in human lung and breast cancer. J Histochem Cytochem 45: 703-709, 1997.

19. Caudroy S, Polette M, Tournier JM, et al: Expression of the extracellular matrix metalloproteinases inducer (EMMPRIN) and the matrix metalloproteinase- 2 in bronchopulmonary and breast lesion. J Histochem Cytochem 47: 1575-1580, 1999.

20. Bordator LC, Li X, Toole B, et al: Expression of EMMPRIN by oral squamous cell carcinoma. Int J Cancer 85: 347-352, 2000.

21. Kanekura T, Chen X and Kanzaki T: Basigin (CD147) is expressed on melanoma cells and induces tumor cell invasion by stimulating production of matrix metalloproteinases by fibroblasts. In J Cancer 99: 520-528, 2002.

22. Sameshima T, Nabeshima K, Toole BP, et al: Expression of EMMPRIN (CD147), a cell surface inducer of matrix metalloproteinases, in normal human brain and gliomas. Int $\mathrm{J}$ Cancer 88: 21-27, 2000.

23. Nabeshima K, Suzumiya J, Nagano M, et al: EMMPRIN, a cell surface inducer matrix metalloproteinases (MMPs), is expressed in T-cell lynphomas. J Pathol 202: 341-351, 2004.

24. Thorns C, Feller AC and Merz H: EMMPRIN (CD147) is expressed in Hodgkin's lymphoma and anaplastic large cell lymphoma. An immunohistochemical study of 60 cases. Anticancer Res 22: 1983-1986, 2002.

25. Yan L, Shahied L, Tang Y, Kesavan P and Nakada MT: Tumorhost interactions. Preclinica 2: 3-8, 2004.

26. Tang Y, Nakada MT, Kesavan P, et al: Extracellular matrix metalloproteinase inducer stimulates tumor angiogenesis by elevating vascular endothelial growth factor and matrix metalloproteinases: Cancer Res 65: 3193-3199, 2005.

27. Dolo V, Ginestra A, Violini S, et al: Ultrastructural and phenotipic characterization of CABA I, a new human ovarian cancer cell line. Oncol Res 9: 129-138, 1997.

28. Zucker S, Hymowitz M, Rollo EE, et al: Tumorigenic potential of extracellular matrix metalloproteinasen inducer. Am J Pathol 158: 1921-1928, 2001.

29. Lehti K, Valtanen H, Wickstrom S, et al: Regulation of Membrane-type-1 Matrix Metalloproteinase activity by its cytoplasmic domain. J Biol Chem 275: 15006-15013, 2000.

30. Basu G, Liang WS, Stephan AD, et al: A novel role for cyclooxigenase-2 in regulating vascular channel formation by human breast cancer cells. Breast Cancer Res 8: R69, 2006.

31. Taraboletti G, Roberts D, Liotta LA and Giavanazzi R: Platelet thrombospondin modulates endothelial cell adhesion, motility, and growth: a potential angiogenesis regulatory factor. J Cell Biol 111: 765-772, 1990.

32. Carmeliet P: Mechanisms of angiogenesis and arteriogenesis. Nat Med 6: 389-395, 2000.

33. Sood AKKM, Coffin JE, Yang M, Seftor EA, Gruman LM, Gershenson DM and Hendrix MJ: Functional role of matrix metalloproteinases in ovarian tumor cell plasticity. Am J Obstet Gynecol 190: 899-909, 2004. 